Research Article

\title{
Association between Very Low Dietary Protein Intake and Subsequent Falls in Community-Dwelling Older Adults in the United States
}

Marika Haritos Paul ${ }^{1,{ }^{+}}$, Mary Beth Arensberg $2,{ }^{+},{ }^{*}$, Judy R. Simon ${ }^{3,+}$, Satya S. Jonnalagadda ${ }^{2,{ }^{+},}$ Suzette L. Pereira ${ }^{2,+}$, Jamie S. Partridge ${ }^{4,+}$, Joseph A. Rosenthal ${ }^{1,+}$

1. The Ohio State University, Columbus, OH, USA; E-Mails: paul.162@osu.edu; Joseph.Rosenthal@osumc.edu

2. Abbott Nutrition Division of Abbott, Columbus, OH, USA; E-Mails: mary.arensberg@abbott.com; satya.jonnalagadda@abbott.com; Suzette.Pereira@abbott.com

3. Maryland Department of Aging, Baltimore, MD, USA; E-Mail: judy.r.simon@gmail.com

4. Bayer Pharmaceuticals, Whippany, NJ, USA; E-Mail: jamie.partridge@bayer.com

+ These authors contributed equally to this work.

* Correspondence: Mary Beth Arensberg, E-Mail: mary.arensberg@abbott.com

Academic Editor: Pilar Pérez-Ros

Special Issue: Frailty in Older Adults

OBM Geriatrics

2020, volume 4, issue 2

doi:10.21926/obm.geriatr.2002120
Received: April 10, 2020

Accepted: May 19, 2020

Published: May 22, 2020

\begin{abstract}
Poor nutrition is linked to frailty and both poor nutrition and frailty are recognized risk factors for falls. This study examined the association between dietary protein intake and subsequent reported falls in community-dwelling older Americans with a history of falls. Other nutritional, functional, and sociodemographic-related variables were also considered in our model. This was a retrospective analysis using data from the U.S. Health and Retirement Study (HRS) and Health Care and Nutrition Study (HCNS), both funded by the U.S. National Institute on Aging. The study population ( $n=3,859)$ was community-dwelling older adults, aged $\geq 65$ years, who reported ever experiencing a fall on the $2012 \mathrm{HRS}$ and had also completed the 2013 HCNS and 2014 HRS. Univariable logistic models were created for all
\end{abstract}

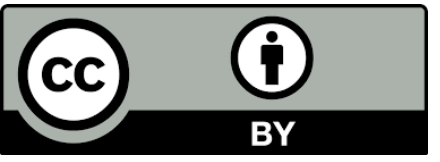

(C) 2020 by the author. This is an open access article distributed under the conditions of the Creative Commons by Attribution License, which permits unrestricted use, distribution, and reproduction in any medium or format, provided the original work is correctly cited. 
variables of interest; variables approaching statistical significance $(p<0.1)$ were included in the initial multivariable logistic model. Backwards selection (cut-off of $p<0.05$ ) was used to create the final model. The incidence of subsequent fall(s) was $13 \%$ greater among individuals with very low protein intake $(<0.4 \mathrm{gm} / \mathrm{kg} /$ day protein) compared to those with higher protein intake $(69.2 \%$ vs $56.2 \%, p=0.02)$. Male gender, living with a partner, weight loss of at least $10 \mathrm{lbs}$ since the last HRS, and low Vitamin D intake were also associated with reporting subsequent fall(s). Older adults reporting very low protein intake had odds of subsequent fall(s) that were 1.65 times that of older adults not reporting very low protein intake, after adjusting for age, sex, weight loss, and difficulty performing Activities of Daily Living $(O R=1.65, p=0.045)$. These findings document very low protein intake may be a risk factor for predicting future falls in older adults with a history of falling. When considering interdisciplinary approaches to frailty, preventive screening for very low/low protein intake among those with a history of falling may help identify who could benefit most from referrals for nutrition education and interventions.

\section{Keywords}

Very low protein intake; subsequent falls; community living older adults; HRS

\section{Introduction}

Frailty and poor nutrition are prevalent, overlapping conditions that impact the functional health of older adults, including their risk for falls [1]. More than one in four older adults fall each year and falling doubles the chances of recurrent and subsequent fall(s) [2]. Falls are the number one cause of injuries and injury deaths among older adults in the United States (U.S.) [3] and falls are also associated with morbidity and premature mortality, reduced quality of life, and increased healthcare costs [4-6]. Frailty is associated with adverse health outcomes and is a strong predictor of disability and multi-morbidity. Frail older adults are likely to have recurrent falls [7] and thus falls prevention remains an important focus across all care settings. Further, given that falls incidence and prevalence increase with age, there is rapid population aging in most countries worldwide, and the health, economic, and quality of life impacts of falls are significant, there is need for evidence-based research on effective falls prevention strategies and programs [8].

In addition to functionality many other factors may contribute to older adults' falls risk, including sociodemographics. Modifiable factors like nutrition status are also key to consider too. Research supports a positive association between malnutrition and falls risk [2, 9, 10]. However, demonstrated links between specific malnutrition-related nutrients (including Vitamin $D$ and protein which have important roles in muscle function, strength, and mass) and falls have not been firmly established [11-14]. Limited studies have specifically considered dietary protein intake and falls $[15,16]$ or subsequent falls [17], even as many U.S. older adults consume less than the U.S. Recommended Dietary Allowance (RDA) for protein [18].

There are few databases that are longitudinal, document the health history of older adults, and include dietary intake data. However, such data are available in the University of Michigan's Health and Retirement Study (HRS), which for more than 20 years has been a leading source of 
information on the changing health and economic circumstances of adults over age 50 in the U.S. HRS data have been used to examine factors related to falls, including the racial and ethnic predictors of falls among older adults [19] and associations between body mass index and central obesity and falls [20]. HRS data also provide an opportunity to consider factors that may impact subsequent falls risk, such as nutrition factors, which may be helpful in developing interdisciplinary multifactor approaches to frailty.

The aim of our study was to examine the association between dietary protein intake and subsequent reported falls in U.S. community-dwelling older adults with a history of falls, using longitudinal data from the HRS. Other nutritional, functional, and sociodemographic-related variables were also considered in our model.

\section{Materials and Methods}

\subsection{Health and Retirement Study (HRS) and Health Care and Nutrition Study (HCNS)}

The HRS is a longitudinal panel study funded by the U.S. National Institute on Aging that surveys a representative sample of approximately 20,000 people in the U.S. Data is collected faceto-face or via telephone by trained survey interviewers; detailed information on HRS data collection instruments is provided on the HRS website [21]. The HRS is conducted on even years and participants aged $\geq 65$ years are specifically asked questions regarding falls. Our retrospective, observational study was completed in 2019 and used data from the 2012 and 2014 waves of the HRS. We defined a fall as an affirmative response to the question "Have you fallen down since the [previous wave survey date] in the last 2 years?" and we defined a subsequent fall as an affirmative answer to this same question on both the 2012 and 2014 HRS.

In odd years, supplemental studies, including the 2013 Health Care and Nutrition Study (HCNS), have also been conducted. The HCNS is the most recent nutrition-related survey that has been completed in conjunction with the HRS. The HCNS was based on the Harvard food frequency questionnaire and the reported daily nutrient intake estimates were determined using Harvard School of Public Health nutrient tables.

Our study population ( $n=3,859)$ was U.S. community-dwelling 2012 HRS participants reporting fall(s) who also completed the 2013 HCNS and the 2014 HRS.

HRS data are de-identified and publicly available, exempting our study from IRB review. This research study complied with current U.S. laws.

\subsection{Study Variables}

For some of the nutrition-related variables in our study, RDAs were used to define intake categories. The protein RDA is $0.8 \mathrm{gm} / \mathrm{kg}$ body weight/day [22]; we considered $\leq 0.8 \mathrm{gm} / \mathrm{kg} /$ day to be low protein intake and $\leq 0.4 \mathrm{gm} / \mathrm{kg} /$ day to be very low protein intake. The Vitamin D RDA is 600-800 IU/day [23]; $\leq 600$ IU was considered low Vitamin D intake. U.S. Dietary Guidelines were used to define calorie intake categories. U.S. Dietary Guideline recommendations range from $1,600-2,000 \mathrm{kcal} /$ day (female) to $2,000-2,600 \mathrm{kcal} /$ day (male) [24]; $\leq 1600 \mathrm{kcal} /$ day was considered to be low calorie intake for females and very low for males. Additional nutrition-related variables we evaluated were Body Mass Index (BMI) and reported weight loss. 
Other variables considered in our model were specific to functionality (grip strength, activities of daily living [ADLs], and instrumental activities of daily living [IADLs]) and sociodemographics (age, gender, race, ethnicity, living arrangements, education, annual household income, and income as a percent of the Federal Poverty Level). To limit the size of our model we did not include further variables that could be related to falls risk such as incidence of underlying disease, cognitive function, medication use, or physical activity.

\subsection{Data Analysis}

The HRS uses weights, clusters, and strata to create nationally representative estimates [21]. For our research, the weighted sample size was $15,975,410$. To compute an odds ratio, univariable logistic models were created for all variables of interest. Variables approaching statistical significance $(p<0.10)$ were included in the initial multivariable logistic model. A more generous $p$ value is often used to identify potential variables that are not significant at the 0.05 level for initial consideration in the model, with the assumption that truly significant variables will be identified after adjusting for relevant covariates. Accordingly, backwards selection (cut-off of $p<0.05$ ) was used to create the final model. All analyses were performed using SAS version 9.3 software (SAS Institute, Inc., Cary, NC, 2011).

\section{Results}

\subsection{Risk of Falls and Associated Factors}

For the research sample of 3,859 older adults, $57.4 \%$ reported subsequent fall(s) on the 2014 HRS. Table 1 identifies the descriptive characteristics of those reporting/not reporting subsequent fall(s). Subsequent falls were associated with lower household income, increased age, and difficulties performing Activities of Daily Living (ADL) and Instrumental Activities of Daily Living (IADL). Incidence of reporting subsequent fall(s) was $13 \%$ greater among individuals with very low protein intake $(\leq 0.4 \mathrm{gm} / \mathrm{kg} /$ day protein) compared to those with higher protein intake (69.2\% vs $56.2 \%, p=0.02$ ). Male gender, living with a partner, weight loss of at least $10 \mathrm{lbs}$ since the last HRS, and low Vitamin D intake were also associated with reporting subsequent fall(s).

Table 1 Descriptive characteristics of sample population who did/did not report subsequent/recurrent fall(s) in 2014 U. S. Health and Retirement Study (HRS) N = 3859.

\begin{tabular}{|c|c|c|c|}
\hline \multirow[b]{3}{*}{ Characteristic } & \multicolumn{3}{|c|}{ Reported Subsequent Fall(s) in 2014 HRS } \\
\hline & No & Yes & \\
\hline & Mean (SD) or N (\%) & Mean (SD) or N (\%) & p-value \\
\hline Education (years) & $13.1(0.1)$ & $12.9(0.1)$ & 0.12 \\
\hline Annual household income & $\$ 70,584(\$ 5,880)$ & $\$ 56,801(\$ 4,671)$ & 0.007 \\
\hline Income as \% Federal Poverty Level (FPL)a & $550 \%(40 \%)$ & $450 \%(30 \%)$ & 0.005 \\
\hline Grip strength $(\mathrm{kg})$ & $24.1(0.8)$ & $23.5(0.7)$ & 0.61 \\
\hline BMI $^{b}$ & $28.1(0.4)$ & $28.7(0.4)$ & 0.34 \\
\hline Daily Vitamin D intake (IU) & $173.7(6.9)$ & $171.1(5.0)$ & 0.76 \\
\hline Daily calories (kcal) & $1855.5(39.6)$ & $1833.7(38.7)$ & 0.69 \\
\hline
\end{tabular}




\begin{tabular}{|c|c|c|c|}
\hline Daily protein (gm) & $73.3(1.8)$ & $72(1.7)$ & 0.60 \\
\hline Age (years) & $74(0.4)$ & $75.4(0.3)$ & 0.006 \\
\hline \# ADL difficulties ${ }^{c}$ & $0.2(0.03)$ & $0.4(0.04)$ & $<0.001$ \\
\hline$\#$ \#IADL difficulties ${ }^{d}$ & $0.2(0.03)$ & $0.5(0.04)$ & $<0.001$ \\
\hline Gender & & & 0.02 \\
\hline Male & $38.0 \%$ & $62.0 \%$ & \\
\hline Female & $46.0 \%$ & $54.0 \%$ & \\
\hline Living arrangements & & & 0.06 \\
\hline Living with spouse/partner & $42.3 \%$ & $57.7 \%$ & \\
\hline Not living with spouse/partner & $43.1 \%$ & $56.9 \%$ & \\
\hline Race & & & 0.74 \\
\hline White & $42.3 \%$ & $57.7 \%$ & \\
\hline Black & $46.6 \%$ & $53.4 \%$ & \\
\hline Other & $45.5 \%$ & $54.5 \%$ & \\
\hline Ethnicity & & & 0.75 \\
\hline Non Hispanic & $42.8 \%$ & $57.2 \%$ & \\
\hline Hispanic & $40.6 \%$ & $59.4 \%$ & \\
\hline Reported weight loss & & & $<0.001$ \\
\hline Lost at least 10 lbs since last HRS & $33.7 \%$ & $66.3 \%$ & \\
\hline No weight loss since last HRS & $45.1 \%$ & $54.9 \%$ & \\
\hline \multicolumn{4}{|l|}{ Very low protein intake $(\leq 0.4$} \\
\hline gm/kg/day) & & & 0.02 \\
\hline$\leq 0.4 \mathrm{gm} / \mathrm{kg} / \mathrm{day}$ & $30.8 \%$ & $69.2 \%$ & \\
\hline$>0.4 \mathrm{gm} / \mathrm{kg} / \mathrm{day}$ & $43.8 \%$ & $56.2 \%$ & \\
\hline \multicolumn{3}{|l|}{ Low protein intake $(\leq 0.8 \mathrm{gm} / \mathrm{kg} /$ day $)$} & 0.29 \\
\hline$\leq 0.8 \mathrm{gm} / \mathrm{kg} / \mathrm{day}$ & $40.8 \%$ & $59.2 \%$ & \\
\hline$>0.8 \mathrm{gm} / \mathrm{kg} / \mathrm{day}$ & $44.2 \%$ & $55.8 \%$ & \\
\hline \multicolumn{3}{|c|}{ Low/very low-calorie intake (<1600 kcal/day) } & 0.20 \\
\hline$\leq 1600 \mathrm{kcal} /$ day & $40.0 \%$ & $60.0 \%$ & \\
\hline$>1600 \mathrm{kcal} /$ day & $44.3 \%$ & $55.7 \%$ & \\
\hline
\end{tabular}

Low Vitamin D intake ( $\leq 600 \mathrm{IU} /$ day for adults aged $65-70$, $\leq 800 \mathrm{IU} /$ day for adults aged $>70$ )

\begin{tabular}{llll}
\hline$\leq 600$ IU or $\leq 800$ IU/day & $42.3 \%$ & $57.7 \%$ & 0.08 \\
\hline$>600$ or $>800$ IU/day & $69.0 \%$ & $31.0 \%$ & \\
\hline
\end{tabular}

${ }^{\mathrm{a}} \mathrm{As}$ calculated in the HRS.

${ }^{\text {b}}$ Body Mass Index (BMI) as calculated in the HRS.

${ }^{c}$ Activities of Daily Living (ADL), measured as the total number difficulty performing or could not perform.

'Instrumental Activities of Daily Living (IADL), measured as the total number difficulty performing or could not perform.

Using male gender as the referent variable, a multivariable logistic model (Table 2) was developed to predict 2014 falls using the sample population reporting fall(s) in the $2012 \mathrm{HRS}$. The final logistic model showed those reporting very low protein intake $(\leq 0.4 \mathrm{gm} / \mathrm{kg} / \mathrm{day})$ had odds of 
reporting subsequent fall(s) that were 1.65 times that of older adults not reporting very low protein intake, after adjusting for age, sex, weight loss, and difficulty performing ADLs (OR=1.65, $p=0.045)$. Compared to males, females were less likely to fall $(O R=0.67, p=0.005)$. Each year of increased age was associated with a small, but elevated risk for falls ( $O R=1.02, p=0.01)$. Compared to individuals who had not lost 10 pounds since completing the previous HRS, those who did report at least a 10-pound loss in body weight were more likely to also report a subsequent fall $(O R=1.59, p=0.005)$. Difficulty performing ADLs was also significantly associated with an increased risk for falls. Individuals who reported difficulty performing one ADL had odds of reporting a subsequent fall 1.48 times that of individuals who reported no difficulty performing ADLs $(O R=1.48, p<0.0001)$. Similarly, a participant reporting difficulty performing two ADLs had odds of reporting a subsequent fall 1.48 times that of individuals who reported difficulty performing one $A D L$, and so forth.

Table 2 Multivariable logistic model predicting falls in 2014 based on a sample population of U.S. Health and Retirement Study (HRS) participants who had reported a fall in the 2012 HRS.

\begin{tabular}{lll}
\hline Variable & Odds Ratio (95\% Cl) & p-value \\
\hline Female & $0.67(0.51,0.89)$ & 0.005 \\
\hline Age & $1.02(1.01,1.04)$ & 0.01 \\
\hline Lost 10 lbs since last HRS & $1.59(1.15,2.18)$ & 0.005 \\
\hline Protein $<.4 g / \mathrm{kg} /$ day & $1.65(1.01,2.69)$ & 0.045 \\
\hline \# ADLs with Difficulty & $1.48(1.22,1.80)$ & $<0.0001$ \\
\hline
\end{tabular}

$\mathrm{N}=1,272$.

R-Squared $=0.065$.

\section{Discussion}

Protein is a key nutrient influencing nearly every bodily system and is critical for maintaining health and quality of life. Low protein intake has been associated with frailty [25] and impaired functionality [26] in older adults and both conditions can be risk factors for falls. The protein RDA is $0.8 \mathrm{gm} / \mathrm{kg}$ for adults, regardless of age. In our study, a number of older adults reported low or very low protein intake, which supports research documenting over one-third of older adults do not meet the protein RDA [18]. The risk for protein deficiency may be significant as emerging research and consensus support increased protein requirements for older adults (1.0-1.6 $\mathrm{gm} / \mathrm{kg} / \mathrm{day}$ ) in part due to decreased absorption/utilization and increased chronic disease [27]. Indeed, the international PROT-AGE Study Group has recommended older adults $>65$ years of age need more dietary protein than younger adults, in part to maintain and regain lean body mass and function [28], which are important to reduce falls risk.

The association between protein intake and falls risk in older adults has not been widely studied. In our analysis, very low protein intake $(\leq 0.4 \mathrm{gm} / \mathrm{kg} /$ day $)$ was associated with a statistically significant increase in subsequent falls, even after adjusting for relevant demographic and functionality variables. In comparison to previous research, one study found no difference in 
protein intake and falls risk but evaluated just females and did not consider subsequent falls [15]. Other research has identified gender differences in risk for falls/recurrent falls including differences related to circumstances leading to falls [29, 30]. Interestingly, our analysis showed an association between male gender and subsequent falls whereas the U.S. Centers for Disease Control and Prevention notes females report more falls [31] and other researchers have described greater falls risk in older women related to factors such as gait variability [32].

It is important to note that the previous study of protein intake and falls among females measured protein intake as below or meeting/above the RDA [15], thus not identifying very low protein intake. When protein intake has been evaluated as a continuous variable, some have reported their tertile analyses tended toward a protective association of subsequent falls (although most were not statistically significant) [17]. Other tertile analyses found no protective association between protein intake and falls risk but did not evaluate subsequent falls risk and documented higher mean protein intake ( $92 \mathrm{gm} /$ day) [16] vs. the means reported in our research (72.0/73.3 gm/day for those with/without subsequent falls). Previous studies have identified a protective association between protein intake and falls in older adults with unintentional weight loss $[16,17]$. Our research also identified weight loss of at least $10 \mathrm{lbs}$ over a two-year period was associated with subsequent fall(s).

Protein needs increase with inadequate calorie intake, but we did not identify an association with subsequent falls risk and low/very low-calorie intake. We did not analyze the specific association between adequate calorie intake and low/very low protein and subsequent falls because previous research has documented older adults not meeting the protein RDA have lower than recommended intakes of energy [18].

Our research documented low Vitamin D intake was associated with subsequent fall(s), supporting a systematic review/meta-analysis reporting an association with Vitamin $D$ and significant falls reduction [13]. Yet a more recent systematic review reported no effect [14] and the U.S. Preventive Services Task Force has concluded Vitamin D supplementation does not prevent falls among older adults [33]. The discrepancies between these results and recommendations and our research may be that our study population had previously reported a fall and their overall mean Vitamin D intakes were much lower than the Vitamin D RDA.

In general, risk factors associated with recurrent falls are similar to those of single falls [34]. Frailty is a risk factor for falls [35] and repeated falls [7]. Thus, in considering the functional variables that had statistical significance in our study, the finding that reported difficulties with ADLs and IADLs were associated with subsequent falls risk was not surprising. A systematic review and meta-analysis of social and demographic pre-disposing characteristics for falls identified that difficulties in at least one ADL or IADL double the risk of falling [36]. And a study using data from the 2004 and 2006 HRS instruments found that whether older adults had falls histories or not, ADL/IADL limitations were consistently associated with higher risks of falls [37].

Our finding of an association between the sociodemographic variables of age and income to subsequent falls risk was also to be expected. Both increased age [38, 39] and lower income [38, 40] have been reported to be linked to increased falls risk. And income has been reported as an important determinant for recurrent falls [41]. What was perhaps unexpected was our finding that living with a spouse/partner had a higher association with subsequent falls risk. While some studies have reported a protective effect of marriage against falling [36] others have found no 
links between marriage and falls risk [42]. Similarly, Yoo et al in looking at repeated falls in older adults found no association to marital status [43].

Falls risk is multifactorial and there were several categories of risk factors for recurrent falls our model did not consider such as underlying disease, cognitive function, assistance from others, medication use, and physical activity. This was a limitation for our study and could have impacted the strength of the associations we identified, particularly as nutritional health often interacts with other falls risk factors such as medical conditions. Another limitation was that as an observational study, there were potential residual and confounding factors, including the inherent limitations of univariable and multivariable logistic modeling. The cut-point for very low protein intake ( $\leq 0.4 \mathrm{gm} / \mathrm{kg} /$ day, which was half the protein RDA) was chosen somewhat arbitrarily; other cut-point(s) could potentially be more clinically meaningful. Another limitation was falls and dietary intake data were self-reported which could result in non-differential misclassification or recall bias.

Strengths of our study included the large and nationally-representative research sample and the HRS use of previously validated survey instruments. The HRS is reported to employ numerous best practices for developing and administering surveys, which contributes to its high-quality data [44]. Also, our study is one of the first to examine the association of dietary protein intake and the risk of falls over time.

\section{Conclusions}

This research documents very low protein intake may be a risk factor for predicting future falls in community dwelling older adults with a history of falling. When considering multifactorial and interdisciplinary approaches to frailty, preventive screening for very low/low protein intake among older adults with a history of falling - including frail older adults - may help clinicians identify individuals who could benefit most from referrals for nutrition interventions such as community nutrition programs, consultation with a registered dietitian nutritionist, and/or oral nutrition supplements. In addition, development and implementation of education programs and policies across care settings and focused on increasing dietary protein for older adults who fall may help improve health outcomes and reduce potential health institution admissions by reducing risk of future falls.

\section{Acknowledgments}

We would like to thank Kirk W. Kerr, PhD for his help with additional data analysis for this paper.

\section{Author Contributions}

All the Authors participated in the concept, design, analysis, writing and revision of the manuscript. This material or similar material has not been and will not be submitted to or published in any other publication.

\section{Funding Source}

This research did not receive any funding from agencies in the public, commercial, or not-forprofit sectors. 


\section{Competing Interests}

MBA, SSJ, and SLP are employees and shareholders of the Abbott Nutrition Division of Abbott which manufacturers science-based nutrition products. At the time of this research, MHP was a consultant for the Abbott Nutrition Division of Abbott and JSP was an employee and shareholder of the Abbott Nutrition Division of Abbott. JRS is an employee of the Maryland Department of Aging which helps establish vibrant communities and supportive services that offer the opportunity for state residents to live healthy and meaningful lives. JAR is an employee of The Ohio State University, the highest-ranked public university in the state and home to the Wexner Medical Center and world-class graduate and undergraduate programs.

\section{References}

1. Dwyer JT, Gahche JJ, Weiler M, Arensberg MB. Screening community-living older adults for protein energy malnutrition and frailty: Update and next steps. J Community Health. 2020; 45: 640-660.

2. Stevens JA, Ballesteros MF, Mack KA, Rudd RA, DeCaro E, Adler G. Gender differences in seeking care for falls in the aged medicare population. Am J Prev Med. 2012; 43: 59-62.

3. Take a stand on falls. Centers for disease control and prevention. Atlanta: United States Department of Health and Human Services; 2017 [2020 February 7]. Available from: https://www.cdc.gov/features/older-adult-falls/index.html.

4. Johnell O, Kanis JA. An estimate of the worldwide prevalence, mortality and disability associated with hip fracture. Osteoporosis Int. 2004; 15: 897-902.

5. Deandrea S, Lucenteforte E, Bravi F, Foschi R, LaVecchia C, Negri E. Risk factors for falls in community-dwelling older people: A systematic review and meta-analysis. Epidemiology. 2010; 21: 658-668.

6. Gillespie LD, Robertson MC, Gillespie WJ, Sherrington C, Gates S, Clemson LM, et al. Interventions for preventing falls in older people living in the community. Cochrane Database Syst Rev. 2012; 12: CD007146.

7. Cheng $\mathrm{MH}$, Chang SF. Frailty as a risk factor for falls among community dwelling people: Evidence from a meta-analysis. J Nurs Scholarsh. 2017; 49: 529-536.

8. Worapanwisit T, Prabpai S, Rosenberg E. Correlates of falls among community-dwelling elderly in Thailand. J Aging Res. 2018; 5: 1-10.

9. Westergren A, Hagell P, Hammarlund CS. Malnutrition and risk of falling among elderly without home-help service-a cross sectional study. J Nutr Health Aging. 2014; 18: 905-911.

10. Tsai AC, Lai MY. Mini nutritional assessment and short-form mini nutritional assessment can predict the future risk of falling in older adults-results of a national cohort study. Clin Nutr. 2014; 33: 844-849.

11. Fitts RH, Romatowski JG, Peters JR, Paddon-Jones D, Wolfe RR, Ferrando AA. The deleterious effects of bed rest on human skeletal muscle fibers are exacerbated by hypercortisolemia and ameliorated by dietary supplementation. Am J Physiol Cell Physiol. 2007; 293: C313-C320.

12. Tieland $M$, van de Rest $O$, Dirks ML, van der Zwaluw N, Mensink M, van Loon LJC, et al. Protein supplementation improves physical performance in frail elderly people: A randomized, double-blind, placebo-controlled trial. J Am Med Dir Assoc. 2012; 13: 720-726. 
13. Murad MH, Elamin KB, Abu Elnour NO, Elamin MB, Alkatib AA, Fatourechi MM, et al. The effect of vitamin D on falls: A systematic review and meta-analysis. J Clin Endorcrinol Metab. 2011; 96: 2997-3006.

14. Bolland MJ, Grey A, Avenell A. Effects of vitamin D supplementation on musculoskeletal health: A systematic review, meta-analysis, and trial sequential analysis. Lancet Diabetes Endocrinol. 2018; 6: 847-858.

15. Larocque SC, Kerstetter JE, Cauley HA, Insogna KL, Ensrud K, Lui LY, et al. Dietary protein and vitamin $D$ intake and risk of falls: A secondary analysis of postmenopausal women from the study of osteoporotic fractures. J Nutr Gerontol Geriatr. 2015; 34: 305-318.

16. Sandoval-Insausti H, Perez-Tasigchana RF, Lopez-Garcia E, Banegas JR, Rodriguez-Artalejo F, Guallar-Castillon P. Protein intake and risk of falls: A prospective analysis in older adults. J Am Geriatr Soc. 2019; 67: 329-335.

17. Zoltick ES, Sahni S, McLean RR, Quach L, Casey VA, Hannan MT. Dietary protein intake and subsequent falls in older men and women: The framingham study. J Nutr Health Aging. 2011; 15: 147-152.

18. Krock-Schoen JL, Archdeacon Price A, Luo M, Kelly OJ, Taylor CA. Low dietary protein intakes and associated dietary patterns and functional limitations in an aging population: A NHANES analysis. J Nutr Health Aging. 2019; 23: 338-347.

19. Nicklett EJ, Taylor RJ. Racial/ethnic predictors of falls among older adults: The health and retirement study. J Aging Health. 2014; 26: 1060-1075.

20. Cho BY, Seo DC, Lin HC, Lohrmann DK, Chomistek AK. BMI and central obesity with falls among community-dwelling older adults. Am J Prev Med. 2018; 54: E59-E66.

21. HRS survey design and methodology. Ann arbor: Health and retirement survey. [2020 February 7]. Available from: https://hrs.isr.umich.edu/documentation/survey-design

22. Institute of medicine. Dietary reference intakes for energy, carbohydrate, fiber, fat, fatty acids, cholesterol, protein, and amino acids / panel on macronutrients, panel on the definition of dietary fiber, subcommittee on upper reference levels of nutrients, subcommittee on interpretation and uses of dietary reference intakes, and the standing committee on the scientific evaluation of dietary reference intakes, food and nutrition board. Washington DC: The National Academies Press; 2005. Available from: https://doi.org/10.17226/10490.

23. Ross AC, Taylor CL, Yaktine AL, Del Valle HB. Dietary reference intakes for calcium and vitamin D. Washington DC: The National Academies Press; 2011.

24. U.S. Department of Health and Human Services and U.S. Department of Agriculture. 20152020 Dietary Guidelines for Americans. 8th Edition. 2015 [2020 February 7]. Available from: http://health.gov/dietaryguidelines/2015/guidelines/

25. Coelho-Junior HJ, Rodrigues B, Uchida M, Marzetti E. Low protein intake is associated with frailty in older adults: A systematic review and meta-analysis of observational studies. Nutrients. 2018; 10: E1334.

26. Gaytan-Gonzalez A, Ocampo-Alfaro MJ, Arroniz-Rivera M, Torres-Naranjo F, GonzalezMendoza RG, Gil-Barreiro $M$, et al. Inadequate protein intake at specific meals is associated with higher risk of impaired functionality in middle to older aged Mexican adults. J Aging Res. 2019; 4: 1-8. 
27. Deutz NE, Bauer JM, Barazzoni R, Biolo G, Boirie Y, Bosy-Westphal A, et al. Protein intake and exercise for optimal muscle function with aging: Recommendations from the ESPEN expert group. Clin Nutr. 2014; 33: 929-936.

28. Bauer J, Biolo G, Cederholm T, Cesari M, Cruz-Jentoft AJ, Morley JE, et al. Evidence-based recommendations for optimal dietary protein intake in older people: A position paper from the PROT-AGE study group. J Am Med Dir Assoc. 2013; 14: 542-559.

29. O YM, El Fakiri F. Gender differences in risk factors for single and recurrent falls among the community-dwelling elderly. SAGE Open. 2015; 5: 1-9.

30. Yang Y, van Schooten KS, Sims-Gould J, McKay HA, Feldman F, Robinovitch SN. Sex differences in the circumstances leading to falls: Evidence from real-life falls captured on video in longterm care. J Am Med Dir Assoc. 2018; 19: 130-135.

31. Bergen G, Stevens MR, Burns ER. Falls and fall injuries among adults aged $\geq 65$ years - United States, 2014. Morb Mortal Wkly Rep. 2016; 65: 993-998.

32. Johansson J, Nordstrom A, Nordstrom P. Greater fall risk in elderly women than in men is associated with increased gait variability during multitasking. J Am Med Dir Assoc. 2016; 17: 535-540.

33. U.S. Preventive Services Task Force. Interventions to prevent falls in community-dwelling older adults: U.S. preventive services task force recommendation statement. JAMA. 2018; 319: 1696-1704.

34. Tariq $H$, Kloseck M, Crilly RG, Gutmanis I, Gibson M. An exploration of risk for recurrent falls in two geriatric care settings. BMC Geriatr. 2013; 13: 106.

35. Kojima G, Kendrick D, Skelton DA, Morris RW, Gawler S, Iliffe S. Frailty predicts short-term incidence of future falls among British community-dwelling older people: A prospective cohort study nested within a randomised controlled trial. BMC Geriatr. 2015; 15: 155.

36. Bloch F, Thibaud M, Dugue B, Breque C, Rigaud AS, Kemoun G. Episodes of falling among elderly people: A systematic review and meta-analysis of social and demographic predisposing characteristics. Clinics. 2010; 65: 895-903.

37. Yamashita T, Noe DA, Bailer AJ. Risk factors of falls in community-dwelling older adults: Logistic regression tree analysis. Gerontologist. 2012; 52: 822-832.

38. Chang VC, Do MT. Risk factors for falls among seniors: Implications of gender. Am J Epidemiol. 2015; 181: 521-531.

39. Ambrose AF, Paul G, Hausdorff JM. Risk factors for falls among older adults: A review of the literature. Maturitas. 2013; 75: 51-61.

40. Florence CS, Bergen G, Atherly A, Burns E, Stevens J, Drake C. Medical costs of fatal and nonfatal falls in older adults. J Am Geriatr Soc. 2018; 66: 693-698.

41. Dai W, Tham Y, Chee M, Tan NYQ, Wong K, Majithia S, et al. Falls and recurrent falls among adults in a multi-ethnic Asian population: The Singapore Epidemiology of Eye Diseases Study. Sci Rep. 2018; 8: 7575.

42. Gale CR, Cooper C, Sayer AA. Prevalence and risk factors for falls in older men and women: The English Longitudinal Study on Ageing. Age Ageing. 2016; 45: 789-794.

43. Yoo JS, Kim CG, Yim JE, Jeon MY. Risk factors of repeated falls in the community dwelling old people. J Exerc Rehabil. 2019; 15: 275-281.

44. Fisher GG, Ryan LH. Overview of the health and retirement study and introduction to the special issue. Work Aging Retire. 2018; 4: 1-9. 


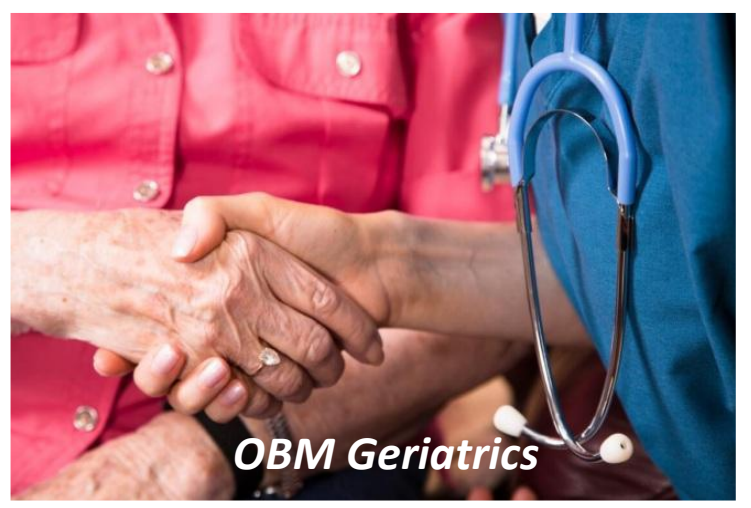

Enjoy $O B M$ Geriatrics by:

1. Submitting a manuscript

2. Joining in volunteer reviewer bank

3. Joining Editorial Board

4. Guest editing a special issue

For more details, please visit:

http://www.lidsen.com/journals/geriatrics 